\title{
Development of Chinese Crop Monitoring Model Using Photosynthetic Production Index
}

\author{
Fengzhi Dai ${ }^{1}$, Ruixiang Bai ${ }^{1}$, Daijiro Kaneko ${ }^{2}$, Qihan You ${ }^{1}$ \\ ${ }^{1}$ College of Electronic Information and Automation, Tianjin University of Science and Technology, \\ 80 MailBox, 1038 Dagunanlu Road, Hexi District, Tianjin 300222, China \\ ${ }^{2}$ Remote Sensing Environmental Monitor, Inc., Japan \\ E-mail:daifz@tust.edu.cn \\ www.tust.edu.cn
}

\begin{abstract}
For monitoring the early stage of crop growth in China, this paper presents a photosynthesis-based monitoring model for grain production. Not only the normalized difference vegetation index and elements such as the growing degree day are considered, the factors of sunshine and the cost of water resource are also considered in the model.
\end{abstract}

Keywords: Crop monitoring, Photosynthesis, Remote sensing, Water resource

\section{Introduction}

In China, huge population and the shortage of water resource becomes the main contradiction between supply and demand of grain. But Chinese grain production is very important because of its huge consumption.

The World Bank, the Worldwatch Institute ${ }^{1}$ and the World Water Council ${ }^{2}$ have warned about the present unsustainable use of water resources for irrigation in China, India, and the U.S., which have significant influence on the total quantity of grain production.

On the condition that both the crop yield and water resource are needed, it is required to monitor the grain production and irrigation water synchronously ${ }^{3,4}$.

Early crop monitoring method is mainly based on the meteorological data such as temperature and precipitation. By the application of satellite, remote sensing data are considered gradually ${ }^{5}$. Thus both the remote sensing and the meteorological data are used in the paper ${ }^{6}$.

\section{Monitoring Crop Production}

Conventional crop studies have correlated grain quantity with the growth index of growing degree day (GDD).

$$
G D D=\frac{T_{\max }+T_{\min }}{2}-T_{b}
$$

Where, $T_{\max }$ and $T_{\min }$ are the maximum and minimum daily air temperature. $T_{\mathrm{b}}$ is the threshold of temperature for the crop, below which the plant physical activity is inhibited and $T_{\mathrm{b}}$ is always set equal to $10^{\circ} \mathrm{C}$.

Rasmussen presented the net primary production (NPP) according to Eq. (2) ${ }^{7}$ :

$$
N P P=\varepsilon \int_{0}^{t}((a N D V I+b) \cdot P A R) d t
$$

where $\varepsilon$ is the efficiency coefficient, $t$ is the time, $a$ and $b$ are regression coefficients, and $P A R$ is the photosynthetically active radiation $\left(\mathrm{MJ} \mathrm{m}^{-2}\right) . N D V I$ is the normalized difference vegetation index.

NPP is calculated by the accumulation of NDVI. And the value NDVI can be measured and calculated by satellite remote sensing. Although NPP in Eq.(2) is the photosynthesis-based model, it does not consider the influence of the temperature.

The former photosynthesis-type crop production index (CPI) is defined in Eq.(3) that is concerning the period from the seeding time $t_{\mathrm{s}}$ to the harvest time $t_{\mathrm{h}}$. PSN is the photosynthesis velocity $\left(\mathrm{g} \mathrm{m}^{-2}\right.$ day $\left.^{-1}\right)$.

$$
\mathrm{CPI}=\int_{t_{s}}^{t_{\mathrm{h}}} P S N \mathrm{dt}
$$

But during the grain growth, low-temperature sterility and high-temperature injury to the grain should be 
considered $^{8,9}$. The present research also develops the photosynthesis-type monitoring method by measuring the water stress so as to improve Eq.(2). The final form of the photosynthesis rate is defined in Eq. $(4)^{10}$, which considered the solar radiation, air temperature, stomatal opening, and vegetation biomass.

$$
P S N=\frac{a \cdot A P A R}{b+A P A R} \cdot f_{S y n}\left(T_{c}\right) \cdot \beta_{s} \cdot e L A I
$$

$a$ and $b$ are Michaelis -Menten constants, APAR is the absorbed photosynthetically active radiation, $T_{c}$ is the canopy temperature, $\beta_{s}$ is the stomatal opening, eLAI is the effective leaf area index, and $f_{S y n}$ is the temperature response function of photosynthesis.

Define $K_{\text {Lster }}$ and $K_{\text {Hster }}$ as the coefficients of lowtemperature and high-temperature that affect the crop growth. $T_{\mathrm{Lster}}$ and $T_{\mathrm{Hster}}$ are the minimum and maximum temperatures for the crop sterility. $F_{\text {ster }}$ in Eq.(5) is the temperature response function for the crop sterility due to both the low and high temperatures:

$$
F_{\text {ster }}\left(T_{c}\right)=\int_{t_{f}}^{t_{r}} f_{\text {Ster }}\left(T_{c}\right) d t=F_{\text {Lster }}\left(T_{c}\right) \cdot F_{H s t e r}\left(T_{c}\right)
$$

where $F_{\text {Lster }}\left(T_{c}\right)=1-\exp \left[k_{\text {Lster }}\left(T_{\text {Lster }}-T_{c}\right)\right]$, $F_{H s t e r}\left(T_{c}\right)=1-\exp \left[k_{H s t e r}\left(T_{c}-T_{H s t e r}\right)\right], t_{f}$ and $t_{r}$ are the times of flowering and ripening.

Eq.(5) is obtained from Fig.1(a) and Fig.1(b), and the result is shown in Fig. $2(\mathrm{a})^{9}$. Here $\mathrm{K}_{\mathrm{Lster}}=0.8, \mathrm{~K}_{\mathrm{Hster}}=0.4$. Thus CPI is revised from Eq.(3) to Eq.(6):

$$
\mathrm{CPI}=\int_{t_{s}}^{\mathrm{t}_{\mathrm{h}}} P S N \cdot F_{\text {Ster }}\left(\mathrm{T}_{\mathrm{c}}\right) \cdot \mathrm{dt}
$$

\section{Data Used in the Model}

Many researchers have presented crop simulation models that involve growth of crops and incorporate remote sensing data ${ }^{11}$. By measuring growth of crop vegetation using remote sensing instead of simulation, the present paper estimates the photosynthesis rate by treating the growth of crop as a known variable.

Estimation of the photosynthesis rate needs daily weather data of solar radiation and air temperature, so that the daily meteorological data must be taken. The world weather data is most suitable for the index CPI because daily regular data are currently observed as weather reports in real time. The CPI requires the NDVI at the positions of the world weather sites using a database derived from NOAA AVHRR ${ }^{12}$

\section{Result of iNDVI}

Fig. 3 shows the distribution of NDVI data in Southeast Asia ${ }^{13}$. And Fig.4 is the integrated NDVI (iNDVI) of the monitoring points in China. If there is neither water stress nor low temperature sterility around the time of flowering, the crop quantity of production should be high in crop areas where the iNDVI is large.

Therefore the large values of the integrated vegetation index at Jinan and Yichan in Fig.4 suggest a good harvest in those areas. The iNDVI is a vegetation growing index, which measures the crop plant density. However, the iNDVI cannot express the effect of a lack of sunshine, or the influence of low-temperature sterility during flowering and filling.

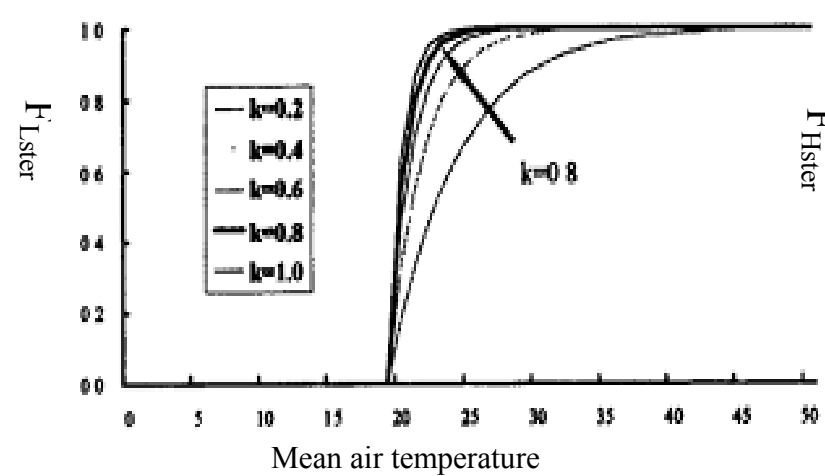

(a) low-temperature sterility

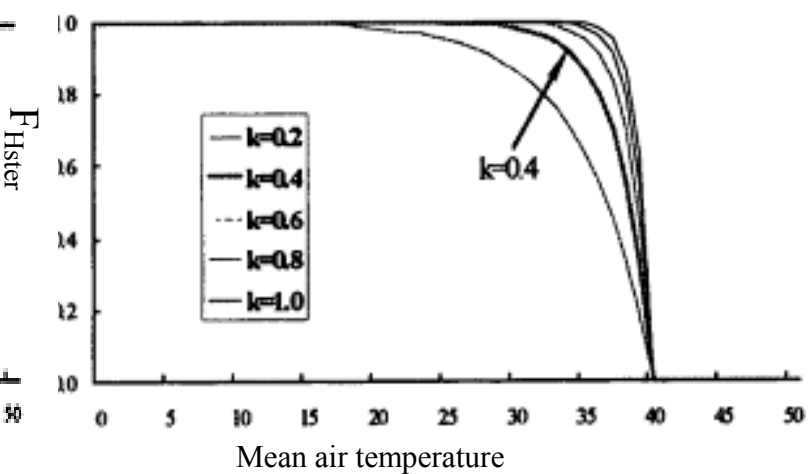

(b) high-temperature injury

Fig.1 Relationship between $\mathrm{F}_{\mathrm{Lster}}$ and $\mathrm{F}_{\mathrm{Hster}}$ to air temperature 


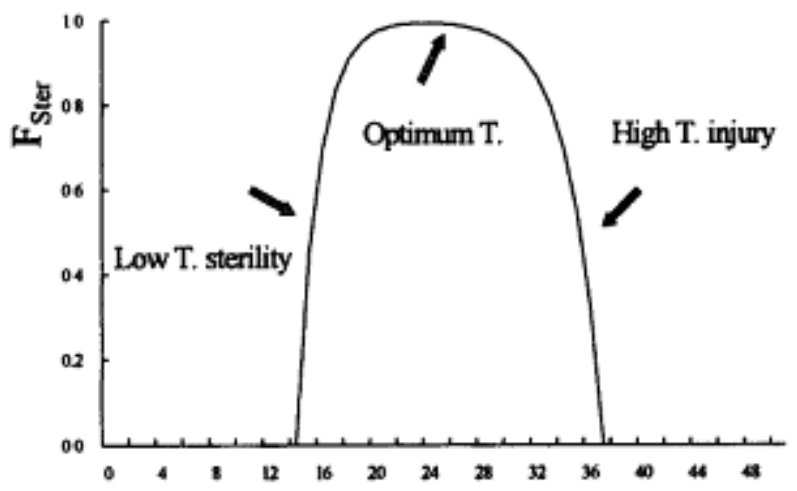

Mean air temperature $\left({ }^{\circ} \mathrm{C}\right)$

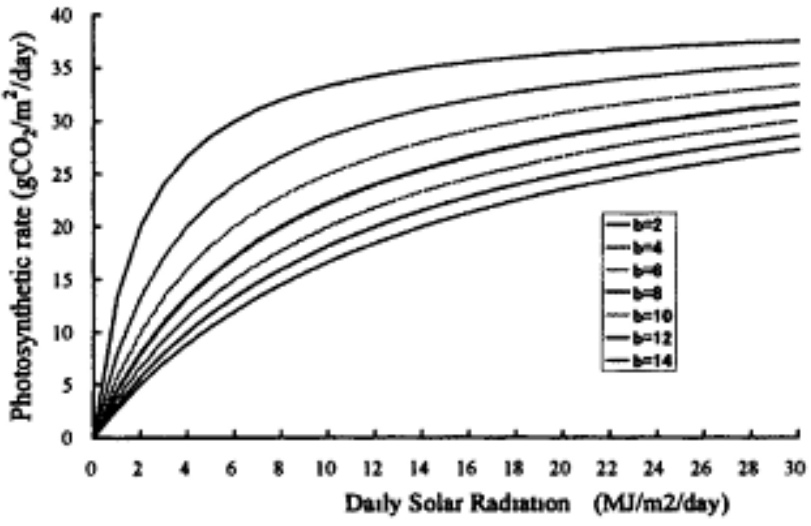

(b) Michaelis -Menten type photosynthetic rate

Fig.2 Function and coefficients in temperature response function for the crop sterility

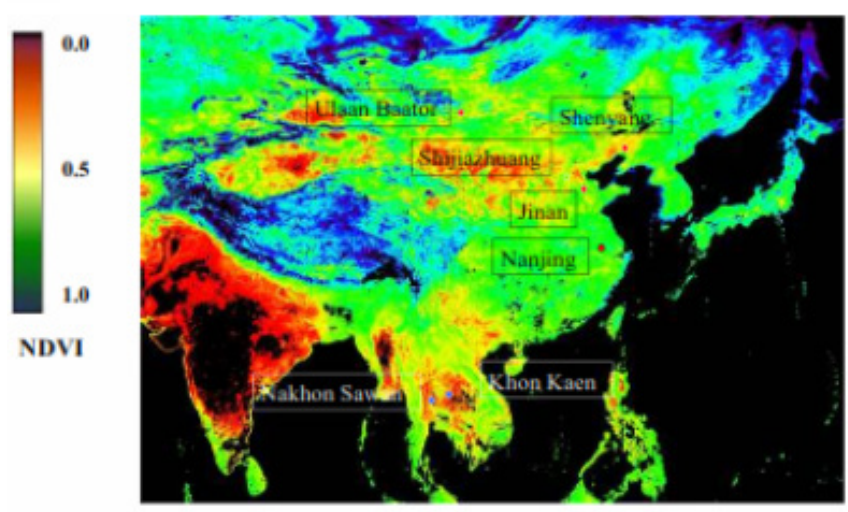

Fig.3 Distribution of NDVI in Southeast Asia

\section{Experiment on Water Stress}

For containing the element of water resource into CPI, the effect of water stress to crop growth is experimented. As we know, the reflectance spectrum of plant leaves changes with the different water stress situation. The paper tests the influence of water stress on rice plant by MODIS and Aster $^{14}$. Rice plants are firstly given the appropriate amount of irrigation, and then the watering is stopped to strengthen water stress to the rice plants. The results of NDVI and NDWI (normalized difference water index) are shown in Fig.5 and Fig.6 respectively ${ }^{3}$.

The relationship between NDVI and NDWI is shown in Fig.7 (Four regions are selected: Matsue, Jinan, Hikawa and Thailand). As we know, if the value NDVI is small, it means that the vegetation amount is small. And for the same value of NDVI, the smaller the value NDWI is, the

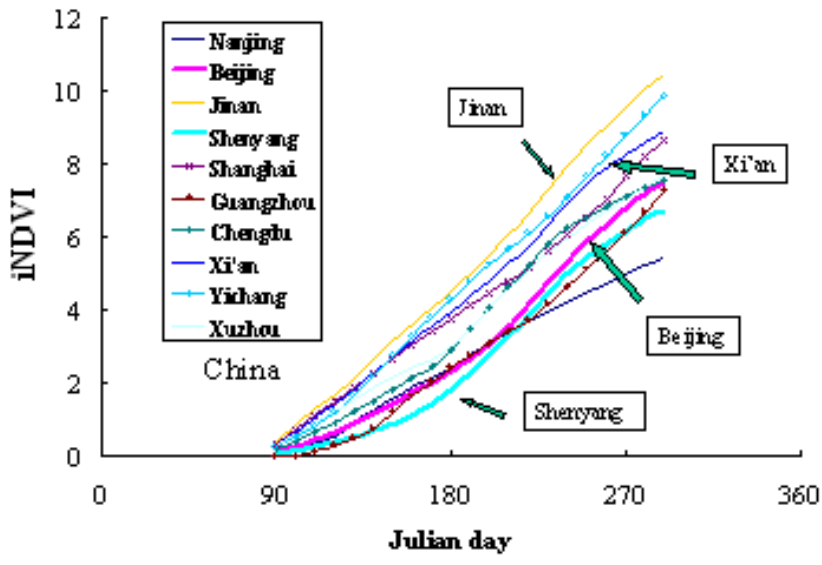

Fig.4 Integrated NDVI (iNDVI) of paddy rice fields in China as a growth index for crop production

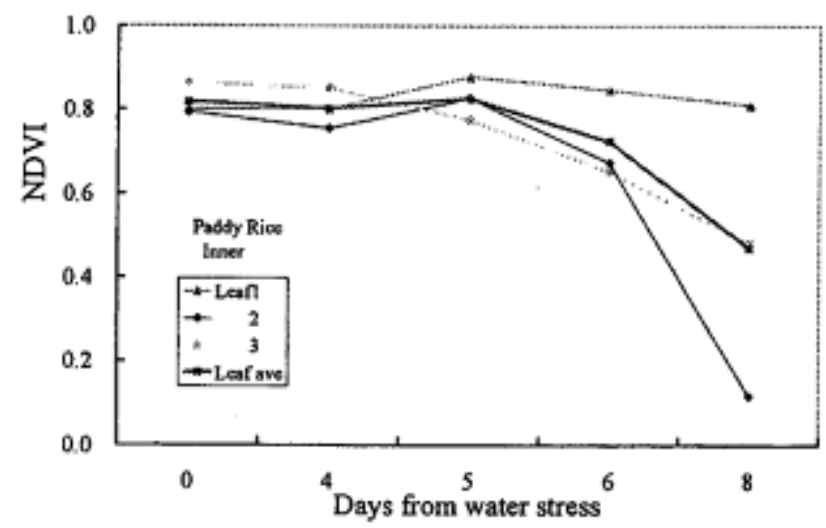

Fig.5 NDVI data in water stress experiment 


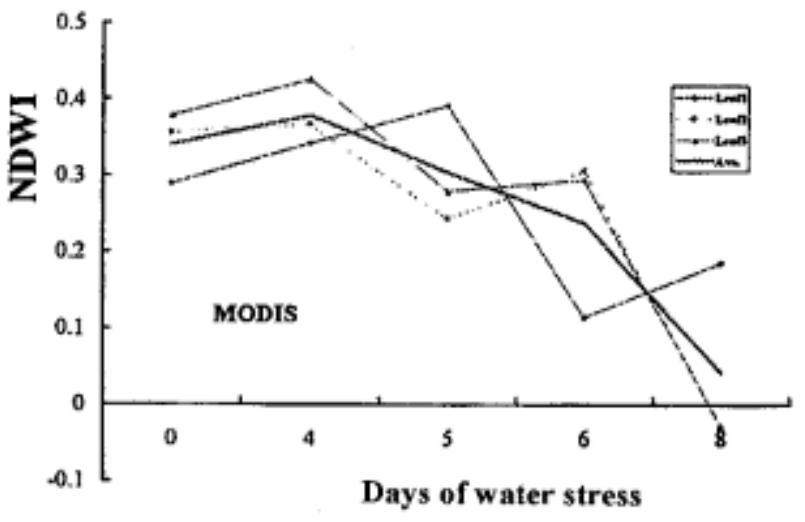

Fig.6 NDWI data in water stress experiment

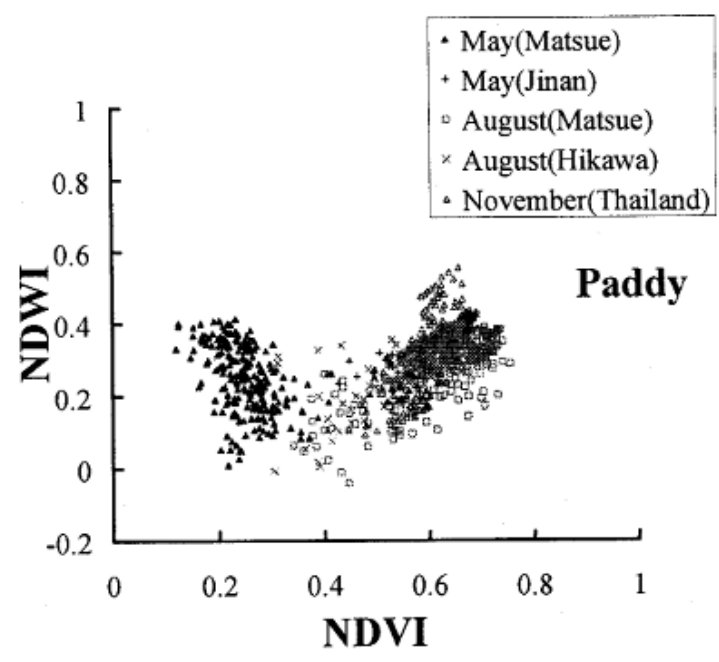

Fig.7 Relationship between NDVI and NDWI

higher the water stress strength is. The distribution of NDVI and NDWI in Fig.7 shows a linear relationship, from which the parameter $\beta_{s}$ (the stomatal opening) in CPI can be defined.

\section{Conclusion}

The paper aims to develop a method of early monitoring the crop quantity in production that would be useful in the present era.

Organization of crop monitoring using the model that is based on daily meteorological and satellite data should be established for China to solve the problem with crop growth $^{15}$. Strategies for crisis management should be available in advance. Technical collaboration and information supply for early warning by the monitoring method proposed in this paper would be useful in guiding agricultural policies of Asian countries.
The proposed photosynthesis-based crop production index CPI considers the factors such as solar radiation, air temperature, vegetation biomass, and stomatal opening using satellite data and world weather data.

\section{Acknowledgements}

The research is partly supported by the Open Foundation (YF11700102) of Key Laboratory for Water Environment and Resources, Tianjin Normal University; and the Research Fund for the Doctoral Program of Higher Education of China (20131208110005).

\section{References}

1. Postel S. Pillar of sand-Can the irrigation miracle last?, W. W. Norton \& Company, Inc., New York, U.S.A. with the Worldwatch Institute, U.S.A. 1999.

2. World Water Council. The 3rd World water forum, Thematic/Regional statements Ministerial declaration, 2003, 105.

3. Daijiro Kaneko. Application of crop production index (CPI) on the Japanese paddy rice and Chinese wheat. Annual Research Report of Chiba University, from NIIElectronic Library Service, 2005,pp. 28-33.

4. Kaneko D, Onishi M, and Ishiyama T. Proposal of early monitoring method for crop production in China and India in the recent era of water resources restriction. Environmental Systems Research, Japan Society of Civil Engineering, 31(2003): 235-244.

5. Food and Agriculture Organization of the United Nations. (FAO FAOSTAT Database, 2003).

6. Kaneko D. Estimation of global solar radiation using world weather data for early monitoring of crop production by satellites, in Proc. 6th symp. water resources, 2002, 677682.

7. Rasmussen MS. Developing simple, operational, consistent NDVI-vegetation models by applying environmental and climatic information: Part II. Crop yield assessment. Int. J. Remote Sensing, 19(1)(1998): 119-137.

8. Matsui T, Namuco OS, Ziska LH and Horie T. Effects of high temperature and $\mathrm{CO}_{2}$ concentration on spikelet sterility in indica rice. Field Crops Research, 51(1997): 213-219.

9. D. Kaneko, M. Ohnishi. Modeling on indices for monitoring crop production using meteorological data and Vegetation Index NDVI. Japanese J. Crop Science. 72(2) (2003): 92-93.

10. D. Kaneko, T. Itohara, M. Ohnishi, T. Ishiyama. Early warning method for rice production using remote sensing and meteorological data: Photosynthetic crop production index. WIT Trans. Ecology and the Environment, Vol.84 (2005): 815-824.

11. Monteith $\mathrm{J}$ L. The quest for balance in crop modeling. Agronomy J., 88(1996): 695-697.

12. Tateishi R. Twenty-year global 4-minute AVHRR NDVI dataset, (CEReS. Chiba University, 2001). 
13. Daijiro Kaneko, Masao Ohnishi, Takashi Ishiyama, Ryutaro Tateishi. Proposal for Early Crop Monitoring Using a Photosynthetic Production Index and Remotely Sensed Data, in Proc. 4th Int. Crop Science Congress, 2004. Available from http://www.cropscience.org.au/icsc2004 /poster/2/8/252_daijir.htm\#TopOfPage

14. Li Jun, Dai Fengzhi, Li Yuan, Yu Chunyu, Hirose Nozomu, Analysis the vegetation and soil moisture in Beijing-Tianjin area to prevent desertification by long-term satellite remote sensing. Applied Mechanics and Materials, Vol. 385-386 (2013): 388-391.

15. Elenita Dano, Elpidio Peria. Emergency or expediency? A study of emergency rice reserve schemes in Asia. A joint publication of AFA and AsiaDHRRA, 2006. Available from http://asiadhrra.org/wordpress/wp-content/uploads/2008/05 /rice\%20reserve\%20scheme.pdf or http://asiadhrra.org /wordpress/2007/12/16/emergency-or-expediency-a-studyof-emergency-rice-reserve-schemes-in-asia/ 